\title{
La interdisciplinariedad en bibliotecología
}

a bibliotecología es una disciplina cuyo cuerpo de conoci-
mientos está integrado por una rica gama de elementos y toca
áreas como la historia, la filosofía o la lingüística, entre muchas otras.

Deesta formalabiblio te cología pue deorien tarse ha ciala produc cióny difusión de libros y conjugar contextos históricos, ideológicos, políticos,pero también pue deabordaras pectos tec noló gicos muyrecientes, como es el caso con los estudios sobre las bases de datos, el uso de las redes de tele comunica ción olaproduc ción de documen tos digitales. Y a través del análisis documental, pone en juego elementos lingüísticos, terminológicos, e incluso estadísticos.

Estas características permiten que los fenómenos propios de la bibliotecologíapuedan abordarse bajo diversos puntos de vista y que el abani co de te mas se pre sen te más am plio para aquel quein da ga en elárea.

Sin embargoes tas cualida des tam bién conlle van ciertos ries gos, entanto que la fuerte interdisciplinariedad que constituye a la bibliotecología puede producir la combinación indiscriminada de métodos y prácticas de otras áreas.

El rescate de los fundamentos bibliotecológicos y de la propuesta de metodologías al interior de la disciplina representan una alternativa para el enriquecimiento del cuerpo de conocimientos de la bibliotecología y, sobre todo, para el fortalecimiento de su identidad.

Georgina Araceli Torres Vargas 